\title{
A Comparative Study of UK and France: The Impact of Education Inequality on Social Mobility in the Two Countries
}

\author{
Zhesu Wang \\ University College London, London, UK
}

\begin{abstract}
In the practice of all countries committed to educational equity, the policies and measures of educational equity are not only affected by the population composition, ethnic type, religious belief and other factors, but also more easily restricted by the political system, economic system, social and cultural development level of a country. Education has become widely associated with ending social inequalities by facilitating the upward mobility of people who obtain a high level of education, no matter their current social class or family background. This paper presented a comparative analysis of education inequality between the UK and France and how does it negatively influence social mobility. After analyzing policy documents and researches from scholars, several hypotheses have been justified. There are not only economic and social factors, but also intelligence level, non-intelligence factors, scale control and quality requirements of the education system, curriculum content, teaching methods, and allocation policies of the education administrative institutions that contributed to social inequality.
\end{abstract}

Key words: education inequality; social mobility; comparative study; most similar systems design; government educational policies

\section{Introduction}

There is a general demand to break the monopoly of the social elite on the privilege of education and make the education right an integral part of everyone's basic rights. Educational equity is a historical concept and is the balance point of rationality and fairness in the continuous evolution of educational system. The development of education plays an important role in promoting the level of political system, economic system, social and cultural development (Green et al., 2011). This paper is to comparatively study and discuss what extent did education inequality negatively influence UK and France' social mobility and what did the government do to minimize education inequality. This comparative study of the UK and France's equity in education policies and practices makes use of the logic and comparative principles provided by the Most Similar Systems Design (MSSD) model, and formulated hypotheses discussion around the topic will be justified.

\section{What Role does Education Play in Social Equity and Mobility?}

Education has become widely associated with ending social inequalities by facilitating the upward mobility of people who obtain a high level of education, no matter their current social class or family background (Breen \& Jonsson, 2005). This is because education widens people's minds, gives them employable skills and knowledge, and equalizes people. 
There is a close relationship between equal access to educational opportunity and the level of social equity.

Firstly, educational activity is a component of social activity, and equal educational opportunity is a component of social equity as education is important among societies and concerns every one of the society (Causa, 2011). Therefore, equal educational opportunity would enable members in society to build social equity. For the second, equal educational opportunity can help to effectively promote social equity. Through fair education, everyone will be able to form a sense of fairness, with fair behavior, and this will certainly help to achieve social fairness. The social vulnerable groups can change their living conditions or reducing social gap only when there is equal educational opportunity. This will help them gradually to improve their social mobility. The equality in economic activities reflect the fairness degree of the society in the political and economic sectors, and the equal opportunity to education can reflect the fairness degree in the cultural and social sectors (Wilkinson, 2002).

\section{Formulation of Hypotheses}

(1) The UK and French governments have carried out policies and legislations to minimize the levels of education inequalities in their countries

(2) Many of these policies and legislations reflecting the current international push to ensure universal access to equal education opportunities worldwide

(3) Despite the well-meaning policy options, both countries have not yet eliminated the problem of unequal educational outcomes among its citizens due to lingering socio-economic disparities among the people

\section{Methodology}

This comparative study of the UK and France's equity in education policies and practices makes use of the logic and comparative principles provided by the Most Similar Systems Design (MSSD) model of comparative studies. The MSSD model is a method used in comparative studies that enables researchers to closely examine systems that are as similar as possible. This model will make it possible to make as many variables can be realistically done (Castern, 2008). The pairing of UK's and France's educational systems was done in accordance with the above logical principles. Both countries are highly industrialized and economically advanced, have highly developed educational systems, and are historically among the most influential nations in many ways. These common characteristics make them a good choice for further studies.

However, we are cognizant of the biggest limitation of the MSSD model, that it is nearly impossible to account for all extraneous variables due to a limited number of countries. But MSSD model is very suitable to study systemic level variables, unlike the Most Different Systems Design (MDSD) model which is best suitable for studying variables at the sub-systemic level. By comparing educational inequalities between the UK and France which seems to be very similar in terms of their economies and corporate governance, we are able to control many of the extraneous variables. This is an appropriate approach since comparative studies require cross-national observations. In our current case, we will explore the range of government policies in the United Kingdom and France that have created policies to deal with educational inequalities in the two countries.

\section{UK Government Policies on Education Inequality}

Education policy reforms in UK's education sector can be traced all the way back to the Tripartite System of 1944. It aimed at bringing about selective education and equality of opportunity. Selective education meant that British students received different education depending on their abilities. At age 11, all students would sit for an assessment to ascertain their ability and then place them into the relevant type of school. Equal opportunity in England and Wales ensured that all learners had a chance to take the $11+$ test. Before 1944, only pupils with good academic equations were the ones to sit for 
the $11+$ test. However, the Tripartite System abated class inequalities because children from middle class backgrounds would end up in grammar school where they can receive an academic education, and sat for exams, while children from socio-economically disadvantaged backgrounds would end up in secondary moderns that only provide basic education and vocational training (Social Mobility Commission, 2017). In 1988, Britain introduced the Education Act that promoted free market principles to bring competition into the education system, which brings more parental control and choice over state institutions, and raises education standards. As a result of increased competitiveness in education, the standards of education improved in the 1990s, but inequalities persisted due to the unequal resources that students from different social classes could gain (Social Mobility Commission, 2017).

The 2010 Coalition and Conservative Government education reforms was introduced to minimize public spending on education in the wake of the 2008 financial crisis. This changes also introduced free schools, forced academisation (refereed to the process by which local authority maintained schools become academies), and the Pupil Premium. These newest reforms continue to raise the standards of education in the United Kingdom, though no evidence can be found to support the idea that free schools and academisation are better than LEA schools. Specifically, the free schools duplicate resources and mostly advantage the middle class. Although it is too early to evaluate the effects of the Pupil Premium, the increased funding of education for the disadvantaged students is definitely going to lead to more education equality in the United Kingdom (Social Mobility Commission, 2017).

\section{French Government Policies on Education Inequality}

From 1959 to 1975, France carried out a series of structural and institutional adjustments of basic education. In 1975, Haby, the minister of Education, passed the Elementary and Secondary Education Reform Program which canceled the professional diversion in the first and second years of junior middle school, and implemented the "unified middle school" in the fifth and sixth grades to further promote equal educational opportunities and democratization in the educational process. From the popularization of compulsory education to the implementation of "unified school", France has established the institutional basis for everyone to receive education equally. At present, scholars have investigated and studied the inequalities in basic education in France and pointed out that the role of education in the generation of social inequality is mainly determined by structural factors. Therefore, the government's commitment to educational system and structural reform is an important measure to eliminate social inequality and improve social mobility (Lewis, 2018).

In order to further promote education equality and improve the quality of education, the French Ministry of Education put forward the slogan of "Le College DE L 'An 2000" at the end of 1998, which required that students with different grades should be mixed into different classes to avoid premature division of majors. In 2001, education minister Jack Lang proposed "republic of middle school (College DE Republique)" to build middles schools for each and every one, and hopes to solve the problems of school failure, students lack of learning motivation and result of different student mix class management question. So far, France's education equality plan has been transformed from macro system construction to specific classroom teaching, which is a huge leap from macro to micro, form to content and quantity to quality. However, there were drawbacks of this policy as students did not have solid basic knowledge after learning, high failure rate of students' study, undisciplined and excessive cultural pride (Lewis, 2018). The current French president, Emmanuel Macron, has declared tackling educational inequality to one of his policy priority area, with a particular focus on investing in primary schools, reducing classroom sizes, declaring compulsory education for any child of 3 years, increasing the number of teachers, and doubling of years (Lewis, 2018). These reforms have also been accompanied by the baccalaureate reform.

\section{Comparative Analysis and Discussion}

Using the MSSD framework of comparative research, it can be proven that there is convergence in policy and practice 
on equity in education between the UK and France. Responding to changes in the international scene, the forces of globalisation and the internationalization of education, most countries have adopted a number of policy and strategies in efforts to make their education systems to be more equitable, both systemic and situational adjustments. In this respect, the United Kingdom and France are no exception.

Since 1940s, the process of improving equity in education in the United Kingdom has been accelerated as only children who scored high IQs could be accorded the best education and the overwhelming majority of average 11-year-olds getting basic numeracy and literacy skills. Most of the action areas of UK education reform after that time had been to bridge the educational attainment gap between children from different backgrounds. The first phase of education reform in the UK lasted until 1988 to standardize the national education curriculum and deal with systemic sources of unequal educational outcomes. In 1990s, UK has instituted a number of educational reforms aimed at creating a more equitable education system that expressively caters for the unique needs of the socio-economically disadvantaged student population. A good example is the introduction of the Pupil Premium in 2011, a funding program for schools to improve education access to the socio-economically disadvantaged students.

Just like the case in the United Kingdom, the French Government mainly touched three broad levels in the last two decades in order to promote education reform and equity in terms of policy and practice, and this included: macro level educational reforms to account for overreaching national interests such as the push to increase the UK's global competitiveness in education and research; the Meso-level at the institutional level geared towards self-made solutions to the problem of unequal educational outcomes, and the micro-level like the push to enhance individual abilities and education outcomes by laying down foundations for each child at an early age.

Due to cross-national differences in history, education system structures and cultural experiences, European countries have adopted divergent policies and practices when responding to the universal issue of educational inequality as well as the effects of globalisation. Due to this path dependent approach to educational reform in addressing inequalities in education attainment, the results are the hybridity of global trends in education equity and national characteristics. When compared to the United Kingdom, France's equity in education has been a question of national heritage since the introduction of compulsory education from age 6 and has remained relatively unchanged until the presidency of Emmanuel Macron. Despite widespread opposition, Macron has made a number of policy changes that are guided by the motto "No child is left behind" which has ushered in range of reforms like reduction in classroom sizes, compulsory education at age 3 , doubling of years, etc. Under the umbrella of education reform as a way of improving social mobility, several common approaches can be identified. Policy and practice convergence includes classroom restructuring, curriculum reform to align teachings to global needs, the introduction of universal access to education, the recognition of the link between socioeconomic status and education outcomes, and increased state funding for education reform.

Theoretical research and policy making need to take different individual' circumstances into account when implementing education equity. Education enables people to have necessary cultural capital to get decent jobs. With decent jobs, there will be high salaries and this is important in maintaining a high quality of life, and it is also the economic basis to enter the wealthy class. In addition, the attainment of high income and high social status does not depend entirely on the level of education-cultural capital, and the characteristics of individuals determined at birth are more important. Education and higher education become the "necessary" path to the workplace, rather than the only capital for upward social mobility (Green et al., 2011). For students to fully develop their academic or other potentials, students' choice should be respected and diversified educational resources should be offered for students to select. Offering diverse educational resources means difference and diversity, but it also means fairness to some extent. In the ultimate sense, it is most equitable (and efficient) 
for each student to develop his or her personality and endowment to the full, because of the diversity and richness of student development.

Educational equality faces up to individual differences and gives up the pursuit of educational homogeneity. It advocates both education for all (reflecting the principle of equality) and proper education for all (reflecting the principle of difference). Homogeneous education with mechanical uniformity, advocating oneness, unity and standardization could not adapt to the uniqueness and comprehensiveness of individual development. In order to fully develop the various factors and characteristics of human beings, diversification in the types of education, curriculum content, teaching methods are the appropriate choices for education. The affirmation of educational diversity opens up broad space for the pursuit of educational equity. How to achieve the full development of students at all levels and improve the social mobility of the country are both considered as important educational policy issues in UK and France.

\section{Conclusions}

The UK and French governments have carried out policies and legislations in place to minimize the levels of education inequalities in their countries. Many of these policies and legislations reflect the current international push to ensure universal access to equal education opportunities worldwide. Despite the well-meaning policy options, both countries have not yet eliminated the problem of unequal educational outcomes among its citizens due to lingering socioeconomic disparities among the people. There are not only economic and social factors that contributed to social inequality, but also intelligence level, non-intelligence factors, scale control and quality requirements of the education system, curriculum content, teaching methods, and allocation policies of the education administrative institutions. It is true, then, that education may help upward social mobility of individuals. However, many university graduates are facing obvious employment difficulties (Breen and Jonsson, 2005). Nowadays, receiving higher education can not determine upward social mobility, but it is considered more as an entry requirement for good employment or avoidance of unemployment. On the other side, people question the "ability of the economy to absorb diploma holders" claimed by human capital theory; they are also considering what other capital is important for upward social mobility besides cultural capital. Therefore, considering the complexation and fragmentation of society, basic education and even higher education are the "necessary" route to the workplace, rather than the only resource for upward social mobility.

\section{Conflicts of Interest}

The author declares no conflicts of interest regarding the publication of this paper.

\section{References}

[1] Breen R., Jonsson, J.O. (2005). Inequality of Opportunity in Comparative Perspective: Recent Research on Educational Attainment and Social Mobility. Annu. Rev. Sociol, (31):223-243.

[2] Causa O., Johansson, Å. (2011). Intergenerational Social Mobility in OECD Countries. OECD Journal: Economic Studies, (1):1-44.

[3] Social Mobility Commission. (2017). Time for Change: An Assessment of Government Policies on Social Mobility. 1997-2017.

[4] Green A., Mason G., Unwin, L. (2011). Education and Inequality: Introduction. National Institute Economic Review, (215):1.

[5] Lewis, H. D. (2018). The French Education System. Routledge.

[6] Programme for International Student Assessment. (2018). Equity in education: Breaking down barriers to social mobility. OECD.

[7] Wilkinson, R. G. (2002). Unhealthy Societies: The Afflictions of Inequality. Routledge. 